\title{
The magnitude of undiagnosed diabetes and Hypertension among adult psychiatric patients receiving antipsychotic treatment
}

${\text { Agete Tadewos Hirigo }{ }^{1 *} \text { and Tesfaye Teshome }}^{2}$

\begin{abstract}
Background: Patients with severe mental illness (SMI) are at increased risk of developing non-communicable diseases that could cause significantly lower life expectancy when compared to the general population. This study aimed to assess the magnitude and predictors of undiagnosed type-2 diabetes and hypertension among adult patients with SMI on antipsychotic treatments.

Methods: A hospital-based cross-sectional study was conducted on 237 psychiatric patients from January to June 2019 at Hawassa University Comprehensive Specialized Hospital, Hawassa, Southern Ethiopia. All relevant information was collected using a structured interviewer-administered questionnaire with a systematic random sampling technique. A total of 4-5 mL of overnight fasting venous blood was collected from each patient. Serum lipid profiles and fasting blood sugar (FBS) were measured using the $\mathrm{A} 25^{\mathrm{TM}}$ BioSystem Random Access chemistry analyzer. To identify predictors of hyperglycemia and raised blood pressure, multiple linear regression analysis was done using SPSS version 23. Statistical significance was set at $\mathrm{p}$ value $<5 \%$.
\end{abstract}

Results: From 247 patients with SMI approached, 237 (58.2\% male and 41.8\% females) were take part in the study giving a response rate of $95.9 \%$. The overall $31.2 \%$ (95\%Cl: $24.1-37.6)$ and $27.8 \%$ (95\%Cl: $23.2-33.4)$ of patients had hyperglycemia and raised BP. The magnitude of prediabetes and type-2 diabetes was $24.9 \%$ (95\%Cl:19.4-30.4), and $6.3 \%$ (95\% Cl: 3.4-10.1), respectively. While the magnitude of prehypertension and hypertension was $23.2 \%$ (95\% Cl: 17.3-29.5) and 4.6\% (95\%Cl: 2.1-8.0), respectively. In multiple linear regression analyses: age, HDL-cholesterol, physical activity and Triglyceride/HDL-cholesterol ratio were positively correlated with FBS. While, HDL-cholesterol, waist circumference, physical activity, total cholesterol/HDL-c ratio, and body mass index were positively correlated with systolic and diastolic blood pressures.

Conclusion: The findings indicate a need to assess blood glucose and blood pressure at baseline before the commencement of any antipsychotic therapy and during therapeutic follow up to manage any increasing trends. Moreover, close monitoring of patients with severe mental illness on antipsychotic therapy is exclusively recommended.

Keywords: Severe mental illness, Hypertension, Diabetes

\footnotetext{
*Correspondence: agetetadewos@yahoo.com; tadewosa@gmail.com

${ }^{1}$ College of Medicine and Health Science, Faculty of Medicine, School

of Medical Laboratory Sciences, Hawassa University, P.O. Box 1560, Hawassa, Ethiopia

Full list of author information is available at the end of the article
}

\begin{abstract}
Background
Patients with severe mental illnesses [SMI] have a high risk of developing metabolic disturbances that include obesity, type-2 diabetes, dyslipidemia, hypertension (HTN) and metabolic syndrome [1]. Besides, patients with SMI have two to three times higher chance of mortality rate and significantly low life expectancy when
\end{abstract}

c) The Author(s) 2020. This article is licensed under a Creative Commons Attribution 4.0 International License, which permits use, sharing, adaptation, distribution and reproduction in any medium or format, as long as you give appropriate credit to the original author(s) and the source, provide a link to the Creative Commons licence, and indicate if changes were made. The images or other third party material in this article are included in the article's Creative Commons licence, unless indicated otherwise in a credit line to the material. If material is not included in the article's Creative Commons licence and your intended use is not permitted by statutory regulation or exceeds the permitted use, you will need to obtain permission directly from the copyright holder. To view a copy of this licence, visit http://creativeco mmons.org/licenses/by/4.0/. The Creative Commons Public Domain Dedication waiver (http://creativecommons.org/publicdomain/ zero/1.0/) applies to the data made available in this article, unless otherwise stated in a credit line to the data. 
compared to the general population [2, 3]. This is due to the presence of existing comorbidities with SMI like diabetes mellitus, HTN, obesity and lack of attention in the mental health clinics especially in developing and low-income countries $[4,5]$. Patients with SMI could be affected highly with type- 2 diabetes and hypertension $[6$, 7].

HTN can affect $35 \%-61 \%$ of patients with bipolar disorder and $19 \%-58 \%$ of schizophrenic patients [8]. Besides, the prevalence of type- 2 diabetes ranges from $10-15 \%$ in schizophrenic patients and $8-17 \%$ among patients with bipolar disorder [8]. The study report from London UK indicated $16 \%$ of the overall estimated prevalence of Type 2 diabetes in people with severe mental problems [9]. While other study conducted in South Africa indicated about $32 \%$ and $8 \%$ prevalence of HTN and type- 2 diabetes among long-term psychiatric patients, respectively [10].

Different studies that conducted in Ethiopia showed the prevalence of type- 2 diabetes in the general population ranging from $1.9 \%-12.2 \%$, like $1.9 \%$ [11], 6.5\% [12] and $12.2 \%$ [13] in South region of Ethiopia, 3.3\% [14], 6.8\% [15] and 10.2\% [16] in Amhara region, and 6.5\% in Addis Ababa [17]. While, the prevalence of HTN in the general population was $10.5 \%$ in Hawassa, South Ethiopia [13], 19.1\% in Addis Ababa, Ethiopia [17], 24.43\% in Dire Dawa, East-Ethiopia [18], 16\% in Tigray, North-Ethiopia [19] and 12.5\% in Debre Markos, Northwest Ethiopia [20].

Different studies highlighted an elevated prevalence of type-2 diabetes [13, 16] and HTN [13, 17-19] among patients with SMI receiving antipsychotic therapy. However, only one study revealed a $7.3 \%$ prevalence of undiagnosed type-2 diabetes among psychiatric patients in Ethiopia [21] and data regarding undiagnosed type-2 diabetes and HTN among the depicted patients in Ethiopia are very scarce. Therefore, this study aimed to assess the magnitude and its predictors of undiagnosed type- 2 diabetes and HTN among adults with SMI receiving antipsychotic therapy.

\section{Methods}

\section{Study setting, design, and population}

This study was conducted in Hawassa University comprehensive specialized Hospital, Southern Nations Nationalities, and Peoples Region (SNNPR) from January to June 2019. Hawassa is the capital city of the SNNPR region and located $275 \mathrm{~km}$ distant from Addis Ababa, the capital city of Ethiopia. This institution based cross-sectional study was conducted among psychiatric patients who had a minimum of one-year regular follow up in the psychiatric department. All patients with SMI, aged greater than or equal to 18 years and who had received the current antipsychotic medication at least for 12 months were eligible for the study. In addition, stabilizing treatment was given for patients before consenting to the study. However, patients with previously diagnosed and known type2diabetes and HTN were not included in the study based on the objective of this study.

\section{Sample size and sampling technique}

The sample size assumption was based on a $16 \%$ proportion of type-2 diabetes among psychiatric patients using a single population proportion formula at $95 \%$ confidence interval (CI) and marginal error of 5\% [9]. In addition, a $20 \%$ non-response rate was considered and the final sample size calculated to be 247 . A systematic random sampling technique was applied to select the study participants from psychiatric patients in the psychiatric outpatient department.

\section{Definition of terms}

\section{Severe mental illness}

Its length of disease and the disability it produces often defines it. The illnesses include disorders that produce psychotic symptoms, such as schizophrenia, schizoaffective disorder, and severe forms of other disorders, such as major depression and bipolar disorders. In addition, the illnesses that produce distortions of perception, delusions, hallucinations, and unusual behaviors are sometimes called thought disorders [22].

According to the American Diabetes Association (ADA) criteria, prediabetes (impaired fasting glucose) is defined as fasting blood sugar (FBS) $100-125 \mathrm{mg} /$ $\mathrm{dl}$; whereas type 2-diabetes is defined as the presence of $\mathrm{FBS} \geq 126 \mathrm{mg} / \mathrm{dl}$ [23]. Undiagnosed type-2 diabetes is defined as patients having formerly undiagnosed or unknowingly elevated FBS level that desired the minimum concentration $(\geq 126 \mathrm{mg} / \mathrm{dl})$ to attain diabetes definition [23].

Pre-HTN is defined as systolic blood pressure (SBP) 120-139 mmHg and a diastolic blood pressure (DBP) $80-89 \mathrm{mmHg}$ in the absence of any result influencing factors [24]; whereas HTN is defined as SBP $\geq 140$ / $\mathrm{DBP} \geq 90 \mathrm{mmHg}$ [24]. In addition, undiagnosed HTN is defined as patients having unknowingly elevated blood pressure that desired the minimum level $(\mathrm{BP} \geq 140 / 90 \mathrm{mmHg})$ to attain the HTN definition [24].

\section{Data collection and assessments}

Socio-demographic data like age, sex, education, marital status, ethnicity, occupation and religion; behavioral data such as khat chewing, smoking, and alcohol taking and clinical data like FBS, BP, type of mental disorder, duration of disease and type of treatments were collected by the interviewer-administered structured questionnaires. 
Before measuring BP, each patient was asked regarding alcohol/caffeine intake, smoking, stressful condition, and bathing for $30 \mathrm{~min}$ before taking a measurement. Then psychiatric nurses who were working in the psychiatric department measured each participant's blood pressure from the left arm in sitting position. In addition, two BP measurements was taken from each patient within a 3-min difference using a digital electronic sphygmomanometer (Omron, Healthcare, Japan) and then the average was taken to address individuals' BP status. Moreover, weight and height measurements were taken from the individuals based on the WHO stepwise guideline [25], using an Adult's digital electronic scale that has both weight and height scales. Body mass index (BMI) was calculated as (weight $/$ height $^{2}$ ) and classified as $\mathrm{BMI}<18.5 \mathrm{~kg} / \mathrm{m}^{2}$ for underweight, $18.5-24.9 \mathrm{Kg} /$ $\mathrm{m}^{2}$ for normal weight, $25-29.9 \mathrm{~kg} / \mathrm{m}^{2}$ for overweight and $\geq 30 \mathrm{~kg} / \mathrm{m}^{2}$ for obesity [26]. Furthermore, the WHO stepwise technique [27] was applied to measure WC of the patients with non-stretching tape.

Overnight fasting blood was collected from each participant for determining serum lipid profiles (total cholesterol [TC], HDL-cholesterol [HDL-c], and triglycerides [TGs]) and FBS using A25 $5^{\mathrm{TM}}$ BioSystem Random Access chemistry analyzer. All chemicals for serum biochemical analysis were from Linear manufacturers (Linear chemicals, Montgat, Spain).

\section{Statistical analysis}

Data of each questionnaire was checked, entered into and analyzed using Statistical Package for Social Sciences (SPSS) Version 23. Descriptive statistics such as frequency and percentages were applied to summarize categorical variables. Besides normally distributed continuous variables were tabulated via means and standard deviation, while median and interquartile range (IQR) were applied for data with skewed distribution. Pearson's correlation coefficient was used to find out the relationship of FBS, SBP, and DBP with different independent variables in all groups. Linear regression models also were analyzed to find out the independent factors that affecting FBS, SBP and DBP, and to determine significant predictors. It was accepted statistically significant when a p-value $<0.05$ at $95 \%$ CI.

\section{Data quality}

Quality of data collection tool was checked by pretesting of $10 \%$ questionnaires before conducting actual data collection. All essential restructuring of the questionnaire was done based on the pretest response. Trained nurses who were working in psychiatric departments participated in data collection; while laboratory technologists manage blood samples collection as well as laboratory diagnoses. During the initial day of contact, patients were advised to come with overnight fasting for the subsequent appointment, and only patients come with overnight fasting gave blood samples. Commercially prepared quality control samples that contained the target values were performed daily before running the patients' samples to ensure the proper functioning of chemistry analyzer, laboratory chemicals and technical performance with the strict adherence of standard operating procedures (SOPs).

\section{Results \\ Socio-demographic and behavioral characteristics of the study population}

Out of the total 247 patients with severe mental illness approached, 10 of them were excluded from the study (4 patients were known type- 2 diabetic, 4 patients were known hypertensives and 2 patients were refused to take part in the study). The overall 237 [138 (58.2\%) males and 99 (41.8\%) females] have participated in the study with a mean age of $31.7 \pm 10.9$ years old. The median duration since the diagnosis of SMI was 3 and raging from 1 to 16 years, while the mean duration since the starting of antipsychotic treatment was $4.8( \pm 2.6)$ years. In addition, $129(54.4 \%)$ of participants were protestant in religion, $29.1 \%$ were jobless and $22.8 \%$ were students. Of the total patients, about 15 (7.2\%) were smokers, 21 (8.9\%) were khat chewers, and 14 (5.9\%) were drinking alcohol. Majority of the patients, 203 (85.7\%) had inactive lifestyle, 53 (22.3\%) were overweight to obese $\left(\mathrm{BMI} \geq 25 \mathrm{~kg} / \mathrm{m}^{2}\right)$ and $26(11 \%)$ were underweight $\left(\mathrm{BMI}<18.5 \mathrm{~kg} / \mathrm{m}^{2}\right)$ (Table 1). Of the total 125 males: 9.4\%, $11.6 \%$, and $17.4 \%$ were drinking alcohol, smoking cigarette, and had sedentary lifestyles, while of 89 female participants: $1 \%, 1 \%$, and $4.2 \%$ were drinking alcohol, smoking cigarette and had sedentary lifestyle. Furthermore, 22.8\%, 19.4\%, and $34.2 \%$ of participants were using chlorpromazine, risperidone, and combined type of antipsychotic agents.

\section{The magnitude of prehypertension, hypertension, prediabetes, and type- 2 diabetes}

Overall 74 (31.2\%, 95\%CI: 24.1-37.6) and 66 (27.8\%, 95\%CI: 23.2-33.4) of the study patients had hyperglyce$\mathrm{mia}(\mathrm{FBS}>100 \mathrm{mg} / \mathrm{dl})$ and raised $\mathrm{BP}(\geq 120 / 80 \mathrm{mmHg})$, respectively. In addition, 55 (23.2\%; 95\% CI: 17.3-29.5) participants had prehypertension and 11 (4.6\%; 95\%CI: 2.1-8.0) had stage-I hypertension. While, 59 (24.9\%; 95\%CI: 19.4-30.4) and 15 (6.3\%; 95\% CI: 3.4-10.1) participants had prediabetes and type 2 diabetes, respectively.

The proportion of type- 2 diabetes, prediabetes, and prehypertension were higher in males, whereas the rate of hypertension was higher in females. The proportion of prediabetes, type-2 diabetes, prehypertension, and hypertension was higher among physically inactive 
Table 1 Socio-demographic, behavioral and biochemicals characteristics of the study subjects

\begin{tabular}{|c|c|c|c|c|c|}
\hline Variables & Category & n (\%) & Variables & Category & n (\%) \\
\hline \multirow[t]{2}{*}{ Sex } & Female & $99(41.8)$ & Marital status, n (\%) & Single & $140(59.1)$ \\
\hline & Male & $138(58.2)$ & & Married & $94(39.7)$ \\
\hline Age, years & mean $( \pm S D)$ & $31.7(10.9)$ & & Divorced/widowed & $3(1.3)$ \\
\hline \multirow[t]{5}{*}{ Age, years } & $\leq 20$ & $42(17.7)$ & Education, n (\%) & Unable to read and write & $11(4.6)$ \\
\hline & $21-30$ & $95(40.1)$ & & Primary & $91(38.4)$ \\
\hline & $31-40$ & $58(24.5)$ & & Secondary & $54(22.8)$ \\
\hline & $41-50$ & $30(12.7)$ & & Certificate and above & $81(34.2)$ \\
\hline & $\geq 51$ & $12(5.1)$ & Smoking, n (\%) & No & $220(92.8)$ \\
\hline \multirow{4}{*}{$\begin{array}{l}\text { Disease duration since its } \\
\text { diagnosis in years }\end{array}$} & Median (IQR) & $3(2.0-5.0)$ & & Yes & $17(7.2)$ \\
\hline & $\leq 3$ & $84(35.4)$ & Alcohol, n (\%) & No & $223(94.1)$ \\
\hline & $4-6$ & $122(51.5)$ & & Yes & $14(5.9)$ \\
\hline & $\geq 7$ & $31(13.1)$ & Khat chewing, n (\%) & No & $216(91.1)$ \\
\hline \multirow[t]{4}{*}{ Religion, n (\%) } & Orthodox & $77(32.5)$ & & Yes & $21(8.9)$ \\
\hline & Protestant & $129(54.4)$ & $\mathrm{TC}, \mathrm{mg} / \mathrm{dl}$ & mean $( \pm S D)$ & $168.2(47.2)$ \\
\hline & Muslim & $25(10.5)$ & $\mathrm{TG}, \mathrm{mg} / \mathrm{dl}$ & Median (IQR) & $\begin{array}{l}111 \\
(83-153)\end{array}$ \\
\hline & Others & $6(2.5)$ & $\mathrm{FBS}, \mathrm{mg} / \mathrm{dl}$ & mean $( \pm S D)$ & $96.9(26.7)$ \\
\hline \multirow[t]{5}{*}{ Ethnicity, n (\%) } & Sidama & $67(28.3)$ & $W C, \mathrm{~cm}$ & mean $( \pm S D)$ & $81.7(10.5)$ \\
\hline & Wolayita & $29(12.2)$ & $\mathrm{SBP}, \mathrm{mmHg}$ & mean $( \pm S D)$ & $119.7(9.3)$ \\
\hline & Amhara & $49(20.7)$ & $\mathrm{DBP}, \mathrm{mmHg}$ & mean $( \pm S D)$ & $78.6(6.7)$ \\
\hline & Oromo & $41(17.3)$ & $\mathrm{HDL}-\mathrm{c}, \mathrm{mg} / \mathrm{dl}$ & mean $( \pm S D)$ & $50(17.7)$ \\
\hline & Others & $51(21.5)$ & Non-HDL-TC & mean $( \pm S D)$ & $117(47.2)$ \\
\hline \multirow[t]{6}{*}{ Occupation } & Employed & $54(22.8)$ & $\mathrm{TC} / \mathrm{HDL}-\mathrm{c}$ ratio & mean $( \pm S D)$ & $3.8(1.8)$ \\
\hline & Merchants & $16(6.8)$ & $\mathrm{TG} / \mathrm{HDL}-\mathrm{c}$ ratio & Median (IQR) & $2.2(1.5-3.7)$ \\
\hline & Farmers & $16(6.8)$ & $\mathrm{BMI}, \mathrm{Kg} / \mathrm{m}^{2}$ & mean $( \pm S D)$ & $22.9(4.7)$ \\
\hline & Students & $54(22.8)$ & $\mathrm{BMI}, \mathrm{Kg} / \mathrm{m}^{2}$ & $<18.5$ & $26(11)$ \\
\hline & housewife & $28(11.8)$ & & $18.5-24.9$ & $158(66.7)$ \\
\hline & Jobless & $69(29.1)$ & & $25-29.9$ & $38(16)$ \\
\hline \multirow{2}{*}{$\begin{array}{l}\text { Exercise (moderate-inten- } \\
\text { sive), n (\%) }\end{array}$} & No & $203(85.7)$ & & $\geq 30$ & $15(6.3)$ \\
\hline & Yes & $34(14.3)$ & & & \\
\hline
\end{tabular}

BMI, body mass index; DBP, diastolic blood pressure; FBS, fasting blood sugar; TC, total cholesterol; TGs, triglycerides; HDL-c, HDL-cholesterol; WC, waist circumference; SBP, systolic blood pressure; [moderate exercise, like brisk walk, hiking on a nature trail, performing chores around the house]; [intensive exercise, causes sweat profusely and makes it difficult to carry on a conversation of any length, like some examples would be running around a track, heavy manual labor, or heavy weightlifting]

patients when compared to those who had the experience of performing light to moderate physical exercise (Table 2).

Regarding occupation, $4.2 \%, 5.1 \%, 8.4 \%$, and $4.2 \%$ of prediabetes was observed among employed patients, housewife, jobless participants, and students, respectively. While the proportion of type- 2 diabetes was, $2.5 \%$ among the employed group and $1.3 \%$ was seen in jobless participants. Pre-hypertension was $5.9 \%$ in the employed group, $5.1 \%$ in jobless participants, and 3.8\% in students. Besides, the prevalence of HTN was $2.5 \%$ in jobless patients with SMI.

The prevalence of prediabetes, type-2 diabetes, prehypertension, and hypertension was higher among patients with schizophrenic disorder when compared to those with other mental disorders: the rates were $14.3 \%, 3.4 \%, 13.5 \%$, and $2.5 \%$, respectively (Table 3).

The magnitude and correlations of undiagnosed type- 2 diabetes and hypertension in relation to different variables The proportion of prediabetes among patients using chlorpromazine was $6.3 \%$, risperidone $(6.8 \%)$, and combination treatment (6.3\%), while the type-2 diabetes rate was higher among patients using combined treatments (3.8\%). Similarly, prehypertension rate among patients receiving chlorpromazine, risperidone and combined treatment was $6.3 \%, 7.2 \%$, and $3.8 \%$, respectively. 
Table 2 The magnitude of undiagnosed diabetes and hypertension in relation with different variables among patients with severe mental illness receiving antipsychoitic agents

\begin{tabular}{|c|c|c|c|c|c|c|}
\hline Variables & Category & Total n (\%) & $\begin{array}{l}\text { Prediabetes } \\
\text { Yes =n (\%) }\end{array}$ & $\begin{array}{l}\text { Diabetes } \\
\text { Yes =n (\%) }\end{array}$ & $\begin{array}{l}\text { Prehypertension } \\
\text { Yes =n (\%) }\end{array}$ & $\begin{array}{l}\text { Hypertension } \\
\text { Yes }=\text { n (\%) }\end{array}$ \\
\hline \multirow[t]{2}{*}{ Sex } & Male & $138(58.2)$ & $32(13.5)$ & $11(4.6)$ & $32(13.5)$ & $3(1.3)$ \\
\hline & Female & $99(41.8)$ & $27(11.4)$ & $4(1.7)$ & $23(9.7)$ & $8(3.4)$ \\
\hline \multirow[t]{2}{*}{ Age, years } & $\leq 40$ & $195(82.3)$ & $41(17.3)$ & $9(3.8)$ & $39(16.5)$ & $6(2.5)$ \\
\hline & $>40$ & $42(17.7)$ & $18(7.6)$ & $6(2.5)$ & $16(6.8)$ & $5(2.1)$ \\
\hline \multirow[t]{2}{*}{$\mathrm{BMI}, \mathrm{Kg} / \mathrm{m}^{2}$} & $<25$ & $184(77.6)$ & $41(17.3)$ & $10(4.2)$ & $34(14.3)$ & $1(0.4)$ \\
\hline & $\geq 25$ & $53(22.4)$ & $18(7.6)$ & $5(2.1)$ & $21(8.9)$ & $10(4.2)$ \\
\hline \multirow[t]{2}{*}{ WC } & Normal & $209(88.2)$ & $50(21.1)$ & $13(5.5)$ & 47 (19.8) & $2(0.8)$ \\
\hline & Abnormal & $28(11.8)$ & $9(3.8)$ & $2(0.8)$ & $8(3.4)$ & $9(3.8)$ \\
\hline \multirow[t]{2}{*}{ Marital status } & Unmarried & $143(60.3)$ & $27(11.4)$ & $6(2.5)$ & $27(28)$ & $4(1.7)$ \\
\hline & Married & $94(39.7)$ & $32(13.5)$ & $9(3.8)$ & $28(11.8)$ & $7(3.0)$ \\
\hline \multirow[t]{2}{*}{ Physical exercise } & Sedentary & $203(85.7)$ & $53(22.4)$ & $13(5.5)$ & $49(20.7)$ & $9(3.8)$ \\
\hline & Moderate & $34(14.3)$ & $6(2.5)$ & $2(0.8)$ & $6(2.5)$ & $2(0.8)$ \\
\hline \multirow[t]{2}{*}{ Smoking } & No & $220(92.8)$ & $55(23.2)$ & $14(5.9)$ & $51(21.5)$ & $11(4.6)$ \\
\hline & Yes & $17(7.2)$ & $4(1.7)$ & $1(0.4)$ & $4(1.7)$ & $0(0.0)$ \\
\hline \multirow[t]{2}{*}{ Alcohol } & No & $223(94.1)$ & $58(24.5)$ & $14(5.9)$ & $55(23.2)$ & $11(4.6)$ \\
\hline & Yes & $14(5.9)$ & $1(0.4)$ & $1(0.4)$ & $0(0.0)$ & $0(0.0)$ \\
\hline \multirow[t]{2}{*}{ Khat chewing } & No & $216(91.1)$ & $55(23.2)$ & $14(5.9)$ & $53(22.4)$ & $9(3.8)$ \\
\hline & Yes & $21(8.9)$ & $4(1.7)$ & $1(0.4)$ & $2(0.8)$ & $2(0.8)$ \\
\hline \multirow[t]{2}{*}{ Disease duration } & $\leq 6$ years & $204(86.1)$ & $47(19.8)$ & $12(5.1)$ & 44 (18.6) & $8(3.4)$ \\
\hline & $>6$ years & $33(13.9)$ & $12(5.1)$ & $3(1.3)$ & $11(4.6)$ & $3(1.3)$ \\
\hline \multirow[t]{2}{*}{$\mathrm{HDL}-\mathrm{c}, \mathrm{mg} / \mathrm{dl}$} & Normal & $140(59.1)$ & $34(14.3)$ & $10(4.2)$ & $38(16.0)$ & $2(0.8)$ \\
\hline & Abnormal & $97(40.9)$ & $25(10.5)$ & $5(2.1)$ & $17(7.2)$ & $9(3.8)$ \\
\hline \multirow[t]{2}{*}{$\mathrm{TG}, \mathrm{mg} / \mathrm{dl}$} & $<150$ & $173(73)$ & $37(15.6)$ & $11(4.6)$ & $39(16.5)$ & $5(2.1)$ \\
\hline & $\geq 150$ & $64(27)$ & $22(9.3)$ & $4(1.7)$ & $16(6.8)$ & $6(2.5)$ \\
\hline \multirow[t]{2}{*}{$\mathrm{TC}, \mathrm{mg} / \mathrm{dl}$} & $<200$ & $178(75.4)$ & $38(16.1)$ & $9(3.8)$ & $41(17.4)$ & $6(2.5)$ \\
\hline & $\geq 200$ & $58(24.6)$ & $20(8.5)$ & $6(2.5)$ & $13(5.5)$ & $\%(2.1)$ \\
\hline
\end{tabular}

BMI, body mass index; FBS, fasting blood sugar; TC, total cholesterol; TGs, triglycerides; HDL-c, HDL-cholesterol; WC, waist circumference; abnormal HDL-c is $<40 \mathrm{mg} / \mathrm{dl}$ in males and $<50 \mathrm{mg} / \mathrm{dl}$ in females

Table 3 The magnitude of undiagnosed diabetes and hypertension in relation to types of mental illness

\begin{tabular}{|c|c|c|c|c|c|}
\hline Variables & $\begin{array}{l}\text { Total } \\
\mathrm{n}(\%)\end{array}$ & $\begin{array}{l}\text { Prediabetes } \\
\text { Yes = n (\%) }\end{array}$ & $\begin{array}{l}\text { Diabetes } \\
\text { Yes =n (\%) }\end{array}$ & $\begin{array}{l}\text { Prehypertension } \\
\text { Yes =n (\%) }\end{array}$ & $\begin{array}{l}\text { Hypertension } \\
\text { Yes = n (\%) }\end{array}$ \\
\hline Schizophrenia disorder & $112(47.3)$ & $34(14.3)$ & $8(3.4)$ & $32(13.5)$ & $6(2.5)$ \\
\hline Schizophrenic form disorders & $9(3.8)$ & $6(1.3)$ & $0(0.0)$ & $1(0.40$ & $0(0.0)$ \\
\hline Schizoaffective disorder & $1(0.4)$ & $0(0.0)$ & $0(0.0)$ & $0(0.0)$ & $0(0.0)$ \\
\hline $\begin{array}{l}\text { Major depressive disorder with psychotic } \\
\text { feature }\end{array}$ & $86(36.3)$ & $26(11)$ & $5(2.1)$ & $20(8.4)$ & $5(2.1)$ \\
\hline Bipolar (I, II, cyclothymic) disorder & $21(8.9)$ & $1(0.4)$ & $1(0.4)$ & $1(0.4)$ & $0(0.0)$ \\
\hline Delusional disorder & $8(3.4)$ & $2(0.8)$ & $1(0.4)$ & $1(0.4)$ & $0(0.0)$ \\
\hline
\end{tabular}

While the rate of hypertension was higher among patients receiving combined treatment $(2.5 \%)$ when compared to patients who were receiving other treatment groups (Fig. 1).

Table 4 shows the Pearson correlation of SBP, DBP and FBS with independent variables. SBP was significantly correlated with age $(\mathrm{r}=0.25, \mathrm{p}<0.0001)$, duration since the diagnosis of disease $(\mathrm{r}=0.15, \mathrm{p}=0.017)$, TG/HDL-c ratio $(\mathrm{r}=0.147, \mathrm{p}=0.023), \mathrm{TC}(\mathrm{r}=0.137, \mathrm{p}=0.035)$ and WC $(\mathrm{r}=0.54, \mathrm{p}<0.0001)$. Besides, TGs and BMI also were significantly correlated with SBP. Age, TG/HDL-c, TC, WC, TGs, BMI, and non-HDL-c were significantly 
Table 4 Pearson's correlation of fasting glucose and blood pressure with independent variables

\begin{tabular}{|c|c|c|c|c|c|}
\hline Variables & Mean ( \pm SD) & Significance & SBP & DBP & FBS \\
\hline \multirow[t]{2}{*}{ Age } & \multirow[t]{2}{*}{$31.7(10.9)$} & Correlation coefficient (r) & 0.253 & 0.223 & 0.195 \\
\hline & & P-value & $<0.0001$ & 0.001 & 0.003 \\
\hline \multirow{2}{*}{$\begin{array}{l}\text { Duration since the diagnosis of } \\
\text { disease }\end{array}$} & \multirow[t]{2}{*}{$3.8(2.7)$} & Correlation coefficient ( $r$ ) & 0.155 & 0.069 & 0.132 \\
\hline & & P-value & 0.017 & 0.291 & 0.042 \\
\hline \multirow[t]{2}{*}{ TG/HDL-c ratio } & \multirow[t]{2}{*}{$2.9(2.0)$} & Correlation coefficient (r) & 0.147 & 0.118 & 0.161 \\
\hline & & P-value & 0.023 & 0.071 & 0.013 \\
\hline \multirow[t]{2}{*}{ TC } & \multirow[t]{2}{*}{$168.2(47.2)$} & Correlation coefficient (r) & 0.137 & 0.151 & 0.257 \\
\hline & & P-value & 0.035 & 0.020 & $<0.0001$ \\
\hline \multirow[t]{2}{*}{ WC } & \multirow[t]{2}{*}{$81.7(10.5)$} & Correlation coefficient ( $r$ ) & 0.541 & 0.437 & 0.060 \\
\hline & & P-value & $<0.0001$ & $<0.0001$ & 0.359 \\
\hline \multirow[t]{2}{*}{$\mathrm{HDL}-\mathrm{C}$} & \multirow[t]{2}{*}{$50.3(17.7)$} & Correlation coefficient ( $r$ ) & 0.026 & 0.054 & 0.033 \\
\hline & & P-value & 0.686 & 0.405 & 0.618 \\
\hline \multirow[t]{2}{*}{ TGs } & \multirow[t]{2}{*}{$123(58.6)$} & Correlation coefficient (r) & 0.201 & 0.190 & 0.110 \\
\hline & & P-value & 0.002 & 0.003 & 0.091 \\
\hline \multirow[t]{2}{*}{ BMI } & \multirow[t]{2}{*}{$22.9(4.7)$} & Correlation coefficient (r) & 0.447 & 0.396 & 0.040 \\
\hline & & P-value & $<0.0001$ & $<0.0001$ & 0.539 \\
\hline \multirow[t]{2}{*}{ TC/HDL-c ratio } & \multirow[t]{2}{*}{$3.8(1.8)$} & Correlation coefficient (r) & 0.084 & 0.068 & 0.241 \\
\hline & & P-value & 0.95 & 0.30 & $<0.0001$ \\
\hline \multirow[t]{2}{*}{ Non-HDL cholesterol } & \multirow[t]{2}{*}{$117(47.2)$} & Correlation coefficient (r) & 0.127 & 0.131 & 0.269 \\
\hline & & P-value & 0.051 & 0.04 & $<0.0001$ \\
\hline \multirow[t]{2}{*}{ LDL-C } & \multirow[t]{2}{*}{$93.3(44.3)$} & Correlation coefficient (r) & 0.082 & 0.09 & $0.259^{*}$ \\
\hline & & P-value & 0.21 & 0.17 & $<0.0001$ \\
\hline
\end{tabular}

BMI, body mass index; FBS, fasting blood sugar; TC, total cholesterol; TGs, triglycerides; HDL-c, HDL-cholesterol; WC, waist circumference; LDL-c, LDL-cholesterol

correlated with DBP. While FBS correlated with age, duration of diseases, TG/HDL-c, TC, HDL-c, TC/HDL-c, non-HDL-c, and LDL-c (Table 4).

In linear regression analysis, all independent variables were significantly associated with FBS ( $p$-value $<0.01$ ). Out of lipid profiles, LDL-c and non-HDL-c were not deliberated as significant predictors. In multiple linear regression analysis: age, physical exercise, TG/HDL-c, HDL-c, and TGs were positively and significantly correlated with FBS, $\mathrm{p}$-value $<0.05$, while TG was negatively correlated with FBS (Table 5).

In addition, SBP and DBP were positively correlated with physical exercise, TC/HDL-c, WC, BMI, and HDLc, p-value $<0.05$. Whereas sex was negatively correlated with SBP and DBP (Table 6).

\section{Discussion}

In this study, 6.3\% (95\% CI: 3.4-10.1) of patients with SMI receiving antipsychotic agents had undiagnosed type-2 diabetes. However, the finding was higher than the rate reported from community-based studies in SouthEthiopia [11], Amhara region [14], and an estimated national prevalence of DM in Ethiopia [28], in which the prevalence rate was $1.9 \%, 3.3 \%$, and $4.36 \%$, respectively. This variation might be attributed to the differences in the management of healthcare, access to health care, the effects of antipsychotic agents and lifestyles of the patients.

The proportion of type- 2 diabetes in the present study was $6.3 \%$ and it was almost comparable with the reports of different studies conducted in psychiatric patients in national as well as international levels, like $6.1 \%$ in Southwest Ethiopia [29], 6.8\% in the UK [30] and 6.5\% in Holland [31]. However, it was lower than the reports of other studies that were conducted in psychiatric patients, for example 7.3\% in Northwest Ethiopia [21], $8 \%$ in South Africa [10], 32\% in California [32], 15.5\% in refugee psychiatric patients [33], 16\% in UK [9], 10.2\% in USA [34] and $12.1 \%$ in Australia [35]. The study design, time duration since the diagnosis of SMI and treatment, generation of antipsychotic agents that have been received by patients and the number of study participants could be a possible reason for the variations.

The studies from Northwest Ethiopia [21] and China [36] reported that females with severe mental illness had a higher rate of undiagnosed diabetes when compared to males. This was not in line with the finding of the present study that revealed males had a higher rate of undiagnosed diabetes $(4.6 \%)$ when compared to females (1.7\%). About $17.4 \%$ of males had sedentary lifestyles 
Table 5 Simple linear regression and multiple linear regression analysis with fasting blood sugar as a dependent variable

\begin{tabular}{|c|c|c|c|c|c|c|c|c|c|c|}
\hline \multirow[b]{2}{*}{ Predictors } & \multicolumn{5}{|c|}{ Simple linear regression analysis for fasting blood sugar } & \multicolumn{5}{|c|}{$\begin{array}{l}\text { Multiple linear regression analysis for fasting blood } \\
\text { sugar }\end{array}$} \\
\hline & B & SE & $\beta$ & $\mathrm{t}$ & p-value & B & SE & $\beta$ & $\mathbf{t}$ & p-value \\
\hline Sex of the participant & 95.2 & 7.999 & 0.612 & 11.9 & $<0.0001$ & -6.533 & 3.617 & -0.042 & -1.806 & 0.072 \\
\hline Age of participant & 2.78 & 0.073 & 0.928 & 38.29 & $<0.0001$ & 0.424 & 0.165 & 0.141 & 2.576 & 0.011 \\
\hline Alcoholism & 89.14 & 26.27 & 0.21 & 3.93 & 0.001 & -1.874 & 7.867 & -0.005 & -0.238 & 0.812 \\
\hline Smoking & 94.23 & 23.63 & 0.25 & 3.987 & $<0.0001$ & -8.614 & 7.221 & -0.023 & -1.193 & 0.234 \\
\hline Physical exercise & 97.877 & 3.057 & 0.902 & 32.02 & $<0.0001$ & 10.773 & 4.812 & 0.099 & 2.239 & 0.026 \\
\hline Schizophrenia & 100.15 & 6.929 & 0.685 & 14.45 & $<0.0001$ & 5.073 & 3.611 & 0.035 & 1.405 & 0.161 \\
\hline Drugs combination & 98.89 & 9.15 & 0.575 & 10.8 & $<0.0001$ & 7.114 & 3.644 & 0.041 & 1.952 & 0.052 \\
\hline TC/HDL-c ratio & 21.519 & 0.691 & 0.897 & 31.15 & $<0.0001$ & 1.148 & 3.252 & 0.048 & 0.353 & 0.724 \\
\hline TG/HDL-c ratio & 23.35 & 1.079 & 0.815 & 21.63 & $<0.0001$ & 9.739 & 3.748 & 0.340 & 2.598 & 0.010 \\
\hline Waist circumference & 1.169 & 0.023 & 0.958 & 51.58 & $<0.0001$ & 0.141 & 0.174 & 0.116 & 0.813 & 0.417 \\
\hline Body mass index & 4.072 & 0.090 & 0.947 & 45.27 & $<0.0001$ & 0.066 & 0.454 & 0.015 & 0.146 & 0.884 \\
\hline LDL-cholesterol & 0.877 & 0.028 & 0.901 & 31.86 & $<0.0001$ & - & - & - & - & - \\
\hline Disease duration & 17.415 & 0.827 & 0.808 & 21.05 & $<0.0001$ & 0.837 & 0.642 & 0.039 & 1.305 & 0.193 \\
\hline HDL-cholesterol & 1.707 & 0.052 & 0.907 & 33.0 & $<0.0001$ & 0.645 & 0.167 & 0.343 & 3.868 & $<0.0001$ \\
\hline Triglycerides & 0.651 & 0.022 & 0.883 & 28.97 & $<0.0001$ & -0.237 & 0.098 & -0.322 & -2.413 & 0.017 \\
\hline Total cholesterol & 0.544 & 0.012 & 0.947 & 45.21 & $<0.0001$ & 0.122 & 0.087 & 0.212 & 1.409 & 0.160 \\
\hline Non-HDL cholesterol & 0.729 & 0.02 & 0.922 & 36.5 & $<0.0001$ & - & - & - & - & - \\
\hline
\end{tabular}

LDL-cholesterol and Non HDL-cholesterol were excluded variables multiple linear analysis; model adjusted for Sex, alcoholism, smoking exercise, schizophrenia and drug combination; B, Unstandardized coefficients; $\beta$, Standardized coefficients; SE, standard error; [FBS, Multiple R: 0.97; R²: 0.941; Adjusted R²: 0.0.937; F: 234.5; degree of freedom: $15 ; p<0.0001]$

when compared to females $(4.2 \%)$ and this might be a possible reason for the variation of diabetes rate between sex in the depicted studies.

A review study revealed that the prevalence of type- 2 diabetes among patients with schizophrenic disorders ranging from $10-15 \%$ [8]. While other studies reported $18.7 \%$ [36], 23.3\% [37] and 23.9\% with 2.4 times of more risks [38]. In this study, the proportione of type-2 diabetes among patients with schizophrenic disorder was 3.4\%. The finding was almost comparable with the study conducted by Correll et al. [39], which indicated 3\% of diabetes mellitus among schizophrenic patients.

In this study, $24.9 \%$ (95\% CI: 19.4-30.4) of psychiatric patients had prediabetes/impaired fasting glucose and this in line with the study conducted in Southwest Ethiopia, which was 26.9\% [28]. However, low rates were reported by different studies, like $4 \%$ [40] and 7\% [41]. The differences might be attributed to the individuals' lifestyle, the diagnostic variability and the scale/guideline that applied to define hyperglycemia (National cholesterol education adult treatment panel III vs. the American Diabetes Association).

Concerning antipsychotic treatment agents, we found $6.3 \%, 6.3 \%, 6.8 \% 3.8 \%$ of patients had impaired fasting glucose among those who were receiving combination treatment, chlorpromazine, and risperidone, respectively.
In support, a review report revealed that chlorpromazine, risperidone and combined antipsychotic treatments alter glucose metabolism from intermediate to high levels [32].

In this study, age was positively and significantly correlated with fasting blood glucose. This finding was in line with the studies conducted by Akter et al. [42] and Zakewos et al. [11]. This might be an increasing body fat with aging, which may have an impact on the proper functioning of insulin and it may consequences insulin resistance. Further beta cells proliferation rate could be affected by the increase of the individuals' age and it could results in more apoptosis than proliferation $[43,44]$.

In this study, the overall 4.6\% (95\% CI: $2.1-8.0$ ) of psychiatric patients had HTN and the finding was lower than the prevalence reported from different studies that conducted in psychiatric patients, for example, 32\% [10], $13.2 \%$ [8], and $42 \%$ [33]. Besides, in this study, $23.2 \%$ (95\% CI: 17.3-29.5) of psychiatric patients had prehypertension and it was higher than the study conducted by Correll et al. which was $10 \%$ [8]. The variations in raised blood pressure and hypertension status might be attributed to differences in the type of antipsychotic drugs that utilized by individuals, duration since the diagnosis of mental problems and treatments, and patients' lifestyle. Moreover, we found that sex, TC/HDL-c, HDL-c, physical activity, WC, and BMI also were significantly 
Table 6 Multiple linear regression analysis with blood pressure as a dependent variable

\begin{tabular}{|c|c|c|c|c|c|c|c|c|c|c|}
\hline \multirow[t]{2}{*}{ Predictors } & \multicolumn{5}{|c|}{ Multiple linear regression analysis for SBP } & \multicolumn{5}{|c|}{ Multiple linear regression analysis for DBP } \\
\hline & B & SE & $\beta$ & $\mathbf{t}$ & p-value & B & SE & $\beta$ & $\mathbf{t}$ & p-value \\
\hline Sex of the participant & -3.646 & 1.487 & -0.020 & -2.452 & 0.015 & -2.963 & 1.087 & -0.024 & -2.725 & 0.007 \\
\hline Age of participant & 0.131 & 0.068 & 0.037 & 1.940 & 0.054 & 0.094 & 0.049 & 0.040 & 1.900 & 0.059 \\
\hline Alcoholism & 1.931 & 3.235 & 0.004 & 0.597 & 0.551 & 2.366 & 2.365 & 0.007 & 1.000 & 0.318 \\
\hline Smoking & -0.489 & 2.969 & -0.001 & -0.165 & 0.869 & -0.750 & 2.171 & -0.003 & -0.346 & 0.730 \\
\hline Physical exercise & 4.967 & 1.978 & 0.038 & 2.511 & 0.013 & 3.369 & 1.446 & 0.040 & 2.329 & 0.021 \\
\hline Schizophrenia & 1.506 & 1.485 & 0.009 & 1.014 & 0.312 & 0.841 & 1.085 & 0.007 & 0.775 & 0.439 \\
\hline Drugs combination & 2.027 & 1.498 & 0.010 & 1.353 & 0.177 & 1.207 & 1.095 & 0.009 & 1.102 & 0.272 \\
\hline TC/HDL-c ratio & 3.225 & 1.337 & 0.112 & 2.412 & 0.017 & 2.444 & 0.977 & 0.130 & 2.501 & 0.013 \\
\hline TG/HDL-c ratio & 1.471 & 1.541 & 0.043 & 0.954 & 0.341 & 0.672 & 1.127 & 0.030 & 0.596 & 0.551 \\
\hline Waist circumference & 0.791 & 0.071 & 0.543 & 11.089 & $<0.0001$ & 0.477 & 0.052 & 0.499 & 9.151 & $<0.0001$ \\
\hline Body mass index & 0.635 & 0.186 & 0.124 & 3.406 & 0.001 & 0.505 & 0.136 & 0.150 & 3.706 & $<0.0001$ \\
\hline Disease duration & 0.141 & 0.264 & 0.005 & 0.535 & 0.593 & -0.095 & 0.193 & -0.006 & -0.493 & 0.622 \\
\hline HDL-cholesterol & 0.567 & 0.069 & 0.252 & 8.261 & $<0.0001$ & 0.391 & 0.050 & 0.264 & 7.792 & $<.0001$ \\
\hline Triglycerides & -0.026 & 0.040 & -0.030 & -0.655 & 0.513 & -0.008 & 0.030 & -0.014 & -0.283 & 0.778 \\
\hline Total cholesterol & -0.064 & 0.036 & -0.092 & -1.783 & 0.076 & -0.044 & 0.026 & -0.097 & -1.688 & 0.093 \\
\hline
\end{tabular}

LDL-c and Non HDL-c were excluded variables from multiple linear analysis; model adjusted for Sex, alcoholism, smoking exercise, schizophrenia and drug combination. SBP, systolic blood pressure; B, Unstandardized coefficients; $\beta$, Standardized coefficients; SE, standard error; DBP, diastolic blood pressure; [SBP, Multiple $R: 0.996 ; R^{2}: 0.993 ;$ Adjusted $R^{2}: 0.993 ; F: 2093.1$; degree of freedom: 15; $\left.p<0.0001\right]$; [DBP, Multiple R: 0.996; $R^{2}: 0.991 ;$ Adjusted R²: 0.991; F: 1685.8; degree of freedom: $15 ; p<0.0001]$

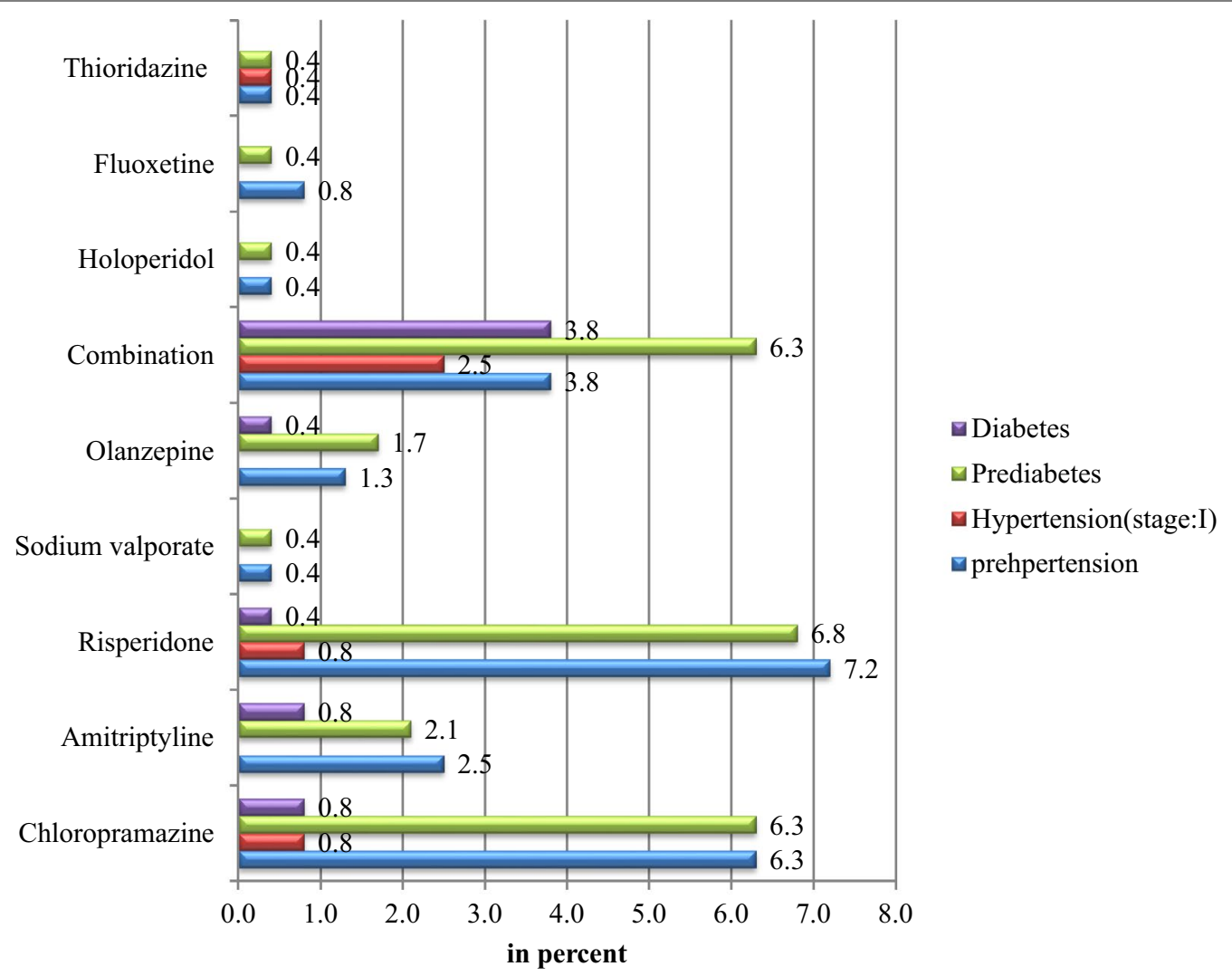

Fig. 1 The magnitude of undiagnosed diabetes and undiagnosed hypertension in relation to antipsychotic treatments among psychiatric patients 
associated with BP. Similarly, different studies reported the association of hypertension with BMI [11, 13, 31, 45], hypertension with WC [11], and hypertension with cholesterol [46]. The alterations in the depicted parameters and physical inactivity in psychiatric patients might be suggestive them to develop cardiovascular complications, despite controlling the severity of mental problem through antipsychotic treatments. In support, psychotic patients have a low life expectancy and a high chance of mortality rate when compared with the general population $[2,3]$.

\section{Limitations of the study}

First, the study did not consider the general population as the control group, however, we tried to compare our findings with previously conducted studies of the general adult population $[11,14]$ regarding diabetes and this might evidence patients with SMI have a higher rate of hyperglycemia/diabetes when compared to the control group. Second, this signifying the evidence of hypertension or diabetes and its causal risk factors adequately is impossible due to the cross-sectional nature of the study. Third, we used FBS to diagnose hyperglycemia/diabetes and an oral glucose tolerance test was not done due to procedural difficulties as well as the psychotic nature of patients. Irrespective of the depicted limits, this study ultimately adds supportive information in the scarce data condition of Ethiopia.

\section{Conclusion}

The increasing trend of hyperglycemia, diabetes, and raised blood pressure were observed among psychiatric patients. The magnitude of type- 2 diabetes among psychiatry patients receiving antipsychotics was higher than the rate of previously conducted several studies of the general populations. Besides, hypertension and undiagnosed type- 2 diabetes were higher among patients receiving combined antipsychotic agents when compared to those receiving single type of treatment agents. Age, TG/HDL-c, HDL-c, physical exercise and TG were significantly associated with FBS, while TC/HDL-c, HDL-c, physical exercise, BMI, WC, and sex were associated with blood pressure.

Therefore, the findings indicate a need to assess blood glucose and blood pressure at baseline before the commencement of any antipsychotic therapy and during therapeutic follow up to manage any increasing trends. The findings also recommend the application of wellcontrolled cohort studies for the assessment of long-term effects of antipsychotic treatment and the disease itself on blood pressure and glucose level. Moreover, this study suggests a need to assess cost-benefit ratio analysis in the decision to treat serious mental illness against the equivalent side effects of medication.

\section{Abbreviations}

BMI: Body mass index; Cl: Confidence interval; HDL-c: HDL-cholesterol; WC: Waist circumference; TG: Triglycerides; SMI: Severe mental illness; SPSS: Statistical package for social sciences.

\section{Acknowledgments}

We want to acknowledge nurses who were working in the psychiatric department for their data collection support and Mr. Abebe Kifle for his blood sample collection support during the study. Further, our appreciation is also extended to patients with SMI for their voluntary involvement in the study.

\section{Authors' contributions}

TT and ATH designed the research, TT performed the research, TT and ATH analyzed data, and ATH wrote the manuscript including critical review. All authors read and approved the final manuscript.

\section{Funding}

This study was financially supported by NORAD project of Hawassa University.

\section{Availability of data and materials}

The dataset of this article is not openly available but it can be accessible on reasonable requests from the corresponding author with authorization of Hawassa University's comprehensive specialized hospital clinical director office.

\section{Ethics approval and consent to participate}

The study was ethically approved by an institutional review board (IRB) of Hawassa University College of Medicine and health sciences (Ref No: IRB 100 09). Go-ahead permission obtained from Clinical and Academic Director Office of Hawassa University Comprehensive Specialized Hospital. All the study participants provided informed consent to participate in this study. All studies on humans described in the present manuscript were carried out with the approval of the responsible ethics committee and in accordance with national law and the Helsinki Declaration of 1975 (in its current, revised form).

\section{Consent for publication}

Not applicable.

\section{Competing interests}

The authors declare that they have no competing interests.

\section{Author details}

${ }^{1}$ College of Medicine and Health Science, Faculty of Medicine, School of Medical Laboratory Sciences, Hawassa University, P.O. Box 1560, Hawassa, Ethiopia.

${ }^{2}$ College of Medicine and Health Science, Faculty of Medicine, Physiology unit, Hawassa University, Hawassa, Ethiopia.

Received: 15 June 2020 Accepted: 27 August 2020

Published online: 07 September 2020

\section{References}

1. De Hert M, Dekker JM, Wood D, Kahl KG, Holt RI, Möller HJ. Cardiovascular disease and diabetes in people with severe mental illness position statement from the European Psychiatric Association (EPA), supported by the European Association for the Study of Diabetes (EASD) and the European Society of Cardiology (ESC). Eur Psychiatry. 2009;24:412-24.

2. Lockett H, Cunningham R, Bagnall C, Arcus K. Cardiovascular disease risk assessment and management in people who experience serious mental illness: an evidence review. Heart, Lung and Circulation. 2016;25:S37.

3. Brown S, Kim M, Mitchell C, Inskip H. Twenty-five year mortality of a community cohort with schizophrenia. Br J Psychiatry. 2010;196:116-21.

4. Saloojee S, Burns JK, Motala AA. Very low rates of screening for metabolic syndrome among patients with severe mental illness in Durban, South Africa. BMC Psychiatry. 2014;14(1):228. 
5. Reilly S, Olier I, Planner C, Doran T, Reeves D, Ashcroft DM, et al. Inequalities in physical comorbidity: a longitudinal comparative cohort study of people with severe mental illness in the UK. BMJ Open. 2015;5(12):e009010.

6. MacRae S, Brown M, Karatzias T, Taggart L, Truesdale-Kennedy M, Walley R, et al. Diabetes in people with intellectual disabilities: a systematic review of the literature. Res Dev Disabil. 2015;47:352-74.

7. Emerson E, Hatton C, Baines S, Robertson J. The physical health of British adults with intellectual disability: cross sectional study. Int J Equity Health. 2016;15:11.

8. Correll CU. Balancing efficacy and safety in treatment with antipsychotics. CNS Spectr. 2007;10(12):S12-2.

9. Das-Munshi J, Ashworth M, Dewey ME, Gaughran F, Hull S, Morgan $C$, et al. Type 2 diabetes mellitus in people with severe mental illness: inequalities by ethnicity and age. Cross-sectional analysis of 588408 records from the UK. Diab Med. 2017;34(7):916-24.

10. Maaroganye K, Mohapi M, Krüger C, Rheeder P. The prevalence of metabolic syndrome and its associated factors in long-term patients in a specialist psychiatric hospital in South Africa. Afr J Psychiatry. 2013;16:6.

11. Zekewos A, Loha E, Egeno T, Wubshet K, Merga Z. Prevalence of Diabetes Mellitus and Associated Factors in Southern Ethiopia: A Community Based Study. Ethiop J Health Sci. 2018;28:4.

12. Aynalem SB, Zeleke AJ. Prevalence of diabetes mellitus and its risk factors among individuals aged 15 years and above in Mizan-Aman town, Southwest Ethiopia, a cross sectional study. Int J Endocrinol. 2016;2018:2018.

13. Kassa A, Woldesemayat EM. Hypertension and Diabetes Mellitus among Patients at Hawassa University Comprehensive Specialized Hospital, Hawassa, Southern Ethiopia. International journal of chronic diseases 2019;2019

14. Animaw W, Seyoum Y. Increasing prevalence of diabetes mellitus in a developing country and its related factors. PLOS ONE. 2017;12(11):e0187670

15. Endris T, Worede A, Asmelash D. Prevalence of Diabetes Mellitus, Prediabetes, and Its Associated Factors in Dessie Town, Northeast Ethiopia: A Community-Based Study. Diabetes Metabolic Syndrome and Obesity: Targets and Therapy. 2019;12:2799-809.

16. Bantie GM, Wondaye AA, Arike EB, Melaku MT, Ejigu ST, Lule A, et al. Prevalence of undiagnosed diabetes mellitus and associated factors among adult residents of Bahir Dar city, northwest Ethiopia: a community-based cross-sectional study. BMJ Open. 2019;9:10.

17. Nshisso LD, Reese A, Gelaye B, Lemma S, Berhane Y, Williams MA. Prevalence of hypertension and diabetes among Ethiopian adults Diabetes \& Metabolic Syndrome. Clin Res Rev. 2012;6(1):36-41.

18. Roba HS, Beyene AS, Mengesha MM, Ayele BH. Prevalence of hypertension and associated factors in Dire Dawa City, Eastern Ethiopia: A community-based cross-sectional study. Int J Hypertens. 2019;2019.

19. Bayray A, Meles KG, Sibhatu Y. Magnitude and risk factors for hypertension among public servants in Tigray, Ethiopia: a crosssectional study. PLoS ONE. 2018;13(10):e0204879.

20. Kiber M, Wube M, Temesgen H, Woyraw W, Belay YA. Prevalence of hypertension, and its associated factors among adults in Debre Markos Town, Northwest Ethiopia: community based cross-sectional study. BMC Res Notes. 2019;12(1):406

21. Asmelash D, Getnet W, Biadgo B, Ambachew S, MelakT, Melese L, et al. Undiagnosed diabetes mellitus and associated factors among psychiatric patients receiving antipsychotic drugs at the University of Gondar Hospital, northwest Ethiopia. Ethiop J Health Sci. 2018;28(1):3-10.

22. Severe Mental IIIness Defined by Duration and Disability. http://www. bhevolution.org/public/severe_mental_illness.page. Accessed 01 June 2020.

23. American Diabetes Association. Classification and diagnosis of diabetes: standards of medical care in diabetes-2019. Diabetes Care 2019;42(1):13-28.

24. Chobanian AV, Bakris GL, Black HR, Cushman WC, Green LA, Jones DW, et al. Hypertension. 2003;42:1206-52.

25. World Health Organization (WHO). Chronic diseases and health promotion: Stepwise approach to surveillance (STEPS). 2010. https://www.who. int/chp/steps/manual/en/

26. Executive Summary of the Clinical Guidelines on the Identification, Evaluation, and Treatment of Overweight and Obesity in Adults. Arch Intern Med 1998:158:1855-67.
27. World Health Organization. WHO Stepwise approach to surveillance (STEPS). Geneva: World Health Organization (WHO); 2008.

28. Aguiree F, Brown A, Cho NH, Dahlquist G, Dodd S, Dunning T, et al. IDF diabetes atlas. 2013

29. Asaye S, Bekele S, Tolessa D, Cheneke W. Metabolic syndrome and associated factors among psychiatric patients in Jimma University Specialized Hospital, South West Ethiopia Diabetes \& Metabolic Syndrome. Clin Res Rev. 2018;12(5):753-60.

30. Coulson M, Agius M, Zaman R. The effect of psychiatric condition and medication on the prevalence of diabetes in a psychiatric out-patient clinic: an audit. Psychiatria Danubina 2012;24:S128-129

31. Cohen D, Stolk RP, Grobbee DE, Gispen-de Wied CC. Hyperglycemia and diabetes in patients with schizophrenia or schizoaffective disorders. Diabetes Care. 2006;29(4):786-91.

32. Mangurian C, Keenan W, Newcomer JW, Vittinghoff E, Creasman JM, Schillinger D. Diabetes prevalence among racial-ethnic minority group members with severe mental illness taking antipsychotics: double jeopardy? Psychiatr Serv. 2017;68(8):843-6.

33. Kinzie JD, Riley C, McFarland B, Hayes M, Boehnlein J, Leung P, et al. High prevalence rates of diabetes and hypertension among refugee psychiatric patients. J Nerv Ment Dis. 2008;196(2):108-12.

34. Manu P, Correll CU, van Winkel R, Wampers M, De Hert M. Prediabetes in patients treated with antipsychotic drugs. J Clin Psychiatry. 2012;73(4):460

35. Foley DL, Mackinnon A, Morgan VA, Watts GF, McGrath JJ, Castle DJ, et al. Predictors of type 2 diabetes in a nationally representative sample of adults with psychosis. World Psychiatry. 2014;13(2):176.

36. Zhang R, Hao W, Pan M, Wang C, Zhang X, Chen DC, et al. The prevalence and clinical-demographic correlates of diabetes mellitus in chronic schizophrenic patients receiving clozapine. Human Psychopharmacology Clinical and Experimental. 2011;26(6):392-6.

37. Bell RC, Farmer $S$, Ries R, Srebnik D. Metabolic risk factors among medicaid outpatients with schizophrenia receiving second-generation antipsychotics. Psychiatr Serv. 2009;60:1686-9.

38. Jerrell JM, McIntyre RS, Tripathi A. Incidence and costs of cardiometabolic conditions in patients with schizophrenia treated with antipsychotic medications. Clin Schizophr Relat Psychos. 2010;4:161-8.

39. Annamalai A, Kosir U, Tek C. Prevalence of obesity and diabetes in patients with schizophrenia. World J Diabetes. 2017;8(8):390.

40. Correll CU, Robinson DG, Schooler NR, Brunette MF, Mueser KT, Rosenheck RA, et al. Cardiometabolic risk in patients with first-episode schizophrenia spectrum disorders: baseline results from the RAISE-ETP study. JAMA Psychiatry. 2014;71(12):1350-63.

41. Whicher CA, Price HC, Holt RI. Mechanisms in endocrinology: Antipsychotic medication and type 2 diabetes and impaired glucose regulation. Eur J Endocrinol. 2018;178(6):245-58.

42. Akter S, Rahman MM, Abe SK, Sultana P. Prevalence of diabetes and prediabetes and their risk factors among Bangladeshi adults: a nationwide survey. Bull World Health Organ. 2014;92:204.

43. Maedler K, Schumann DM, Schulthess F, Oberholzer J, Bosco D, Berney $T$, et al. Aging correlates with decreased $\beta$-cell proliferative capacity and enhanced sensitivity to apoptosis: a potential role for fas and pancreatic duodenal homeobox-1. Diabetes. 2006;55(9):2455-62.

44. Scigliano G, Ronchetti G. Antipsychotic-induced metabolic and cardiovascular side effects in schizophrenia: a novel mechanistic hypothesis. CNS Drugs. 2013;27(4):249-57.

45. Asresahegn H, Tadesse F, Beyene E. Prevalence and associated factors of hypertension among adults in Ethiopia: a community based cross-sectional study. BMC Res Notes. 2017;10(1):629.

46. Sesso HD, Buring JE, Chown MJ, Ridker PM, Gaziano JM. A prospective study of plasma lipid levels and hypertension in women. Arch Intern Med. 2005:165(20):2420-7.

\section{Publisher's Note}

Springer Nature remains neutral with regard to jurisdictional claims in published maps and institutional affiliations. 